\section{A century of chemical warfare: time to stop}

One hundred years ago, in August of 1914, during the first month of World War I, a group of French soldiers attacked German troops and, for the first time in declared warfare, used grenades containing tear gas. ${ }^{1}$ Thus began the current era of chemical warfare, accompanied by an accelerated arms race, in which several old and new compounds were adopted for military use and even reconfigured for maximum lethality.

In the wake of the Aug. 21, 2013 chemical-weapons attack on the suburbs of Damascus, Syria, that killed over 1000 people, $C M A J$ published an editorial in which Patrick and colleagues, ${ }^{2}$ emphasized that "gassing civilian populations is a depraved and depraving act [leading] to a brutalized society destroyed by monsters." In World War I, the use of poisonous gases accounted for over 1.3 million casualties and more than 90000 deaths. ${ }^{3}$ In parallel, major efforts were initiated by the scientific and the medical communities to develop effective countermeasures with only limited success.

The purpose of chemical warfare agents has changed since their initial deployment, from tactical weapon, to strategic deterrent. More recently, we have witnessed an alarming increase in the frequency with which chemical weapons are used, not only in battlefield situations, but also on civilian populations. Tragic examples of this reality include the attack on the Kurds of Halabja in northern Iraq in the late 1980 s, the use of sarin by terrorists in Japan in the mid-1990s, and the current continuing crisis in Syria. ${ }^{2,4}$ The importance of strong and effective measures by the international community to prevent the use of chemical weapons cannot be exaggerated.

International collaborative efforts to identify new and more effective treatments and countermeasures must be expanded and put in place until the nations of the world succeed in closing the curtain on the use of these atrocious agents after 100 years.

\section{Arik Eisenkraft, S. David Gertz, Yitshak Kreiss}

Institute for Research in Military Medicine (Eisenkraft, Gertz, Kreiss), Department of Military Medicine, Faculty of Medicine, The Hebrew University of Jerusalem and The Israel Defense Forces Medical Corps, Jerusalem, Israel.

\section{References}

1. Hilmas CJ, Smart JK, Hill BA. History of chemical warfare. In: Medical aspects of chemical warfare. Tuorinsky SD, editor. Falls Church (VA): Office of the Surgeon General; Washington (DC): Borden Institute, Walter Reed Army Medical Center; 2008;9-76.

2. Patrick K, Stanbrook M, Flegel K. Lest we forget: why the use of chemical weapons must not go unchallenged [editorial]. CMAJ 2013;185:1299.

3. Fitzgerald GJ. Chemical warfare and medical response during World War I. Am J Public Health 2008;98:611-25.

4. Rosman Y, Eisenkraft A, Milk N, et al. Lessons learned from the Syrian sarin attack: evaluation of a clinical syndrome through social media. Ann Intern Med 2014;160:644-8.

\section{CMAJ 2014. DOI:10.1503/cmaj.114-0060}

\section{A little cheese, a big cheese and the novel anticoagulants}

I love my work. I have survived and thrived in the trenches of general practice for the past 35 years. I am a "little cheese," in contrast to the "big cheeses" in large academic centres.

In a $C M A J$ practice article, Moayedi and colleagues ${ }^{1}$ state:

The Canadian Cardiovascular Society guidelines indicate a preference for novel oral anticoagulants, such as dabigatran, rivaroxaban or apixaban, over warfarin for patients with nonrheumatic atrial fibrillation.

I reviewed the cited article, ${ }^{2}$ and in the body of the text there was no unqualified statement that the novel anticoagulants should be used in preference of the warfarin. Instead, the article provides a "conditional recommendation" that "suggests" that when oral anticoagulant therapy is indicated, most patients should receive the novel anticoagulants in preference to warfarin. ${ }^{2}$

I believe that Moayedi and his colleagues at the University of Toronto have been overly enthusiastic in their endorsement of novel anticoagulants. I do not believe the cited reference ${ }^{2}$ supports this bias. I have communicated with Dr. Paul Dorion, one of the authors of the CMAJ article, ${ }^{1}$ several times, and he feels that his enthusiasm is justified.

As a "little cheese" in a smaller community, I rely on CMAJ for honest and untainted guidance in respect of safe medical practice. I ask the authors to review their comments and to perhaps qualify their enthusiasm. I refer the authors to an excellent article in Blood $^{3}$ that does not express a preference for novel anticoagulants, and to my letter, ${ }^{4}$ which offers reasons why a "big cheese" may be so enthusiastic.

One may say that these are only words, but they are words that will influence the prescribing practices of thousands of physicians across Canada and potentially put hundreds of thousands of patients at risk. These are important words.

\section{Ian. L. Mitchell MD}

Family physician, Mitchell Family

Medical Centre Inc., Delta, BC

\section{References}

1. Moayedi Y, Abdel-Qadir HM, Dorian P. Evaluation and care of a patient with new-onset atrial fibrillation. CMAJ 2014;186:204-5.

2. Skanes AC, Healey JS, Cairns JA, et al. Focused 2012 update of the Canadian Cardiovascular Society atrial fibrillation guidelines: recommendations for stroke prevention and rate/rhythm control. Can J Cardiol 2012;28:125-36.

3. Schulman S, Crowther MA. How I treat with anticoagulants in 2102: new and old anticoagulants, and when and how to switch. Blood 2012;119: 3016-23.

4. Mitchell IL. Re: Roots of evidence based medicine [letter]. BCMJ 2009;10:426-7.

\section{CMAJ 2014. DOI:10.1503/cmaj.114-0055}

\section{The authors respond}

We thank Mitchell ${ }^{1}$ for his interest in this topic and in our review. ${ }^{2}$ Our goal was to afford the reader a concise interpretation of the evidence regarding stroke prevention in atrial fibrillation. We fully appreciate the importance of being cautious in the acceptance of recent clinical trial results. However, we respectfully emphasize that the guidelines do indeed "recommend" the newer oral anticoagulants in preference to warfarin: 
We suggest that when OAC [oral anticoagulant] therapy is indicated, most patients should receive dabigatran, rivaroxaban, or apixaban, ... in preference to warfarin. This recommendation places a relatively high value on comparisons with warfarin. ${ }^{3}$

We suggest that readers consult the 2014 update of the atrial fibrillation guidelines when they become available.

Since 2010, four randomized controlled trials have provided high-quality evidence reflecting the safety and efficacy of direct-acting anticoagulants. This breadth of evidence includes over 70000 patients. Both dabigatran and apixaban have been shown to be superior to warfarin in stroke reduction. In the Aristole trial there was a significant mortality benefit of apixaban compared with warfarin. ${ }^{4}$ All of the newer anticoagulants significantly reduced the risk of intracranial hemorrhage. ${ }^{5}$

We agree that guidelines and published studies do not replace clinical judgment, and that individual practitioners should discuss with their patients the risks and benefits of all anticoagulants and take into account patient values and preferences.

\section{Yas Moayedi MD, Husam Abdel-Qadir MD, Paul Dorian MD}

Division of Cardiology and Department of Internal Medicine (Moayedi, Abdel-Qadir, Dorian), University of Toronto, Toronto, Ont.

\section{References}

1. Mitchell IL. A little cheese, a big cheese and the novel anticoagulants [letter]. CMAJ 2014;186:936.

2. Moayedi Y, Abdel-Qadir H, Dorian P. et al. Evaluation and care of a patient with new-onset atrial fibrillation. CMAJ 2014;186:204-5.

3. Skanes AC, et al. Focused 2012 update of the Canadian Cardiovascular Society atrial fibrillation guidelines: recommendations for stroke prevention and rate/rhythm control. Can J Cardiol 2012;28:125-36.

4. Granger $\mathrm{CB}$, et al. Apixaban versus warfarin in patients with atrial fibrillation. N Engl J Med 2011; 365:981-92.

5. Ruff CT, et al. Comparison of the efficacy and safety of new oral anticoagulants with warfarin in patients with atrial fibrillation: a meta-analysis of randomised trials. Lancet 2014;383:955-62.

CMAJ 2014. DOI:10.1503/cmaj.114-0056

\section{How can we best address the tuberculosis epidemic?}

I read with interest the excellent $C M A J$ commentary by Campbell and colleagues, ${ }^{1}$ in which the authors highlight the limitations of current tuberculosis (TB) control strategies for immigration screening.

There has been some recent progress. A new short-course regimen for latent TB infection, which requires just three months of once-weekly rifapentine and isoniazid (3HP), has been shown to be as effective, and perhaps safer, than the existing nine-month regimen of daily isoniazid. ${ }^{2}$ Many of us, if given a choice, would prefer the $3 \mathrm{HP}$ regimen of 12 weekly doses compared to 270 daily doses of isoniazid. Unfortunately, although 3HP has been adopted as a treatment option for latent tuberculosis infection in the United States since 2011, access to this regimen is extremely limited in Canada.

As White and Houben ${ }^{3}$ wrote in a recent editorial, the most direct and equitable way to progress toward elimination of TB in industrialized countries would be to increase funding for TB control in high-burden countries. In 2005, researchers from Montréal, Quebec, showed beautifully that this approach would not only lower rates of TB but, unlike increasing testing and treatment for latent TB infection, would lead to significant cost savings. ${ }^{4}$ As Canadians, we have long been proud supporters of global TB control efforts and our international partnerships and aid efforts must continue.

\section{Jan Hajek MD}

Clinical assistant professor, University of British Columbia, Vancouver, BC

\section{References}

1. Campbell J, Marra F, Cook V, et al. Screening immigrants for latent tuberculosis: Do we have the resources? CMAJ 2014;186:246-7.

2. Sterling TR, Villarino ME, Borisov AS, et al.; TB Trials Consortium PREVENT TB Study Team. Three months of rifapentine and isoniazid for latent tuberculosis infection. N Engl J Med 2011;365:2155-66.

3. White RG, Houben RM. Towards elimination in industrialised countries: expanding diagnosis and treatment of LTBI among immigrants [editorial]. Int J Tuberc Lung Dis 2014;18:380.

4. Schwartzman K, Oxlade O, Barr RG, et al. Domestic returns from investment in the control of tuberculosis in other countries. N Engl J Med 2005;353:1008-20.

CMAJ 2014. DOI:10.1503/cmaj.114-0061

\section{Vaporizer legalization}

I agree with Kahan and Srivastava ${ }^{1}$ that as physicians, we cannot support the smoking of cannabis, for either recreational or medical purposes. Even though a recent, large case-control study ${ }^{2}$ showed no increase in lung cancer related to smoking cannabis, vaporization offers a clear harm-reduction approach to cannabis consumption. Vaporization more efficiently extracts cannabinoids from plant material, decreases the products of combustion and can be used in institutional settings, as has been the case in hospitals in Sherbrooke, Quebec and Calgary.

Vaporizers can be effective harmreduction tools. Only one vaporizer is currently approved by Health Canada, although its hefty price tag of $\$ 600$ keeps it out of the reach of many patients. The use of vaporizers in Canada is also compromised by their illegal status. The import, export, manufacturing and sale of vaporizers in Canada contravenes section 462.2 of the Criminal Code. ${ }^{3}$ This section also provides for a prison sentence of up to six months for the possession of cannabis-related literature, in all provinces except Ontario. ${ }^{3}$

Aside from advocating that this archaic law be repealed nationwide, we should be recommending vaporizers not only to our patients who are being treated with cannabis, but also for those who we know to be using it for recreational purposes.

\section{Ian V. Mitchell MD}

Assistant professor of emergency medicine medicine, University of British Columbia, Vancouver, BC

\section{References}

1. Kahan M, Srivastava A. New medical marijuana regulations: the coming storm. CMAJ 2014;186: 895 .

2. Zhang LR, Morgenstern H, Greenland S. Cannabis smoking and lung cancer risk: Pooled analysis in the International Lung Cancer Consortium. Int $J$ Cancer 2014; June 20. [Epub ahead of print].

3. Criminal Code of Canada: 462.2 - Offence and punishment. Available: http://yourlaws.ca/criminal -code-canada/4622-offence-and-punishment (accessed 2014 June 27)

CMAJ 2014. DOI:10.1503/cmaj.114-0062

In submitting a letter, you automatically consent to having it appear online/in print. All letters accepted for print will be edited for space and style. See www.cmaj.ca for full versions and competing interests. 